\title{
Introduction: New Paths in Civil Defence History
}

Marie Cronqvist, Rosanna Farbøl, and Casper Sylvest

For a number of years after the end of the Cold War and the proclaimed ascendancy of Western liberal democracy, nuclear civil defence and emergency preparedness were considered by many to be a relic of history, a curiosity or vaguely familiar target of ridicule. In the 2020s, this is no longer the case. As expressions of fear and a desire for survival and resilience should the worst happen, institutions and practices of civil defence have both predated and outlived the Cold War. In the age of terrorism, global pandemics, rising political tensions between nuclear armed states, and a deepening climate crisis, emergency preparedness

M. Cronqvist $(\bowtie)$

Department of Communication and Media, Lund University, Lund, Sweden e-mail: marie.cronqvist@kom.lu.se

R. Farbøl · C. Sylvest

Department of History, University of Southern Denmark, Odense, Denmark e-mail: rosfa@sdu.dk

C. Sylvest

e-mail: csy@sdu.dk

M. Cronqvist et al. (eds.), Cold War Civil Defence in Western Europe, https://doi.org/10.1007/978-3-030-84281-9_1 
is once again making headway on the political agenda in many countries. Continuities between Cold War civil defence and new logics of (in)security (Masco 2013; Deville et al. 2014; cf. Collier and Lakoff 2008) have become apparent, and authorities, politicians and defence intellectuals seem to be increasingly interested in updating material infrastructures and revisiting core ideas of civil defence.

In a striking example of the Cold War echoing in our own time, in May 2018 the Swedish Government distributed a leaflet entitled If crisis or war comes to every household in Sweden. It highlighted the importance of emergency preparedness, asking citizens to prepare and stockpile food and necessities and instructing the reader to 'educate yourself!', while providing the location of nearby shelters (MSB 2018). By using an expression already established in the 1940s and repeated constantly throughout the postwar era-'If the war comes'-the Swedish government today is forging a peculiar connection between the Cold War nuclear mindset and twenty-first-century narratives of fear and crises. In Europe, new initiatives are also being introduced by the European Commission in its multibillion-euro research programme Horizon Europe, a part of which prioritises research into 'Civil Security for Society'. Apart from improving situational awareness, data-driven decision-making and the understanding of risk exposures among authorities, the Commission seeks ways to cultivate a "culture of disaster preparedness" for citizens, communities, public administrations, business companies, practitioners...' ${ }^{1}$ The COVID-19 pandemic, which began in 2020 and has wreaked havoc across the globe, has further fuelled demands for emergency preparedness in societies that aim to be resilient in the face of a wide variety of risks. In particular, the dilemma of how to communicate appropriately with the public in times of crisis has multiple parallels in the history of civil defence. Old technologies have also been revived. The pervasive climate crisis has, for example, brought new attention to the use of shelters as vital protection from cyclones, hurricanes and wildfires, concluding a shift that began during the late Cold War away from threats coming from a 'stable enemy' and towards an all-hazards approach to threats posed by 'nonspecific adversaries' (Lakoff 2007).

At the same time, scholars are taking a new interest in risk, resilience and emergency management. A recently funded American project, 'Reinventing civil defence', seeks to develop 'effective non-partisan nuclear risk communication targeted at Millennials' in an effort to inspire change in nuclear weapons politics (Karl and Wellerstein 2017; Karl and Lytle 
2019). Meanwhile, within the developing and highly publicised field of Global Existential Risks, the value of civil defence thinking and material structures like refuges and shelters is being revisited with a view to assessing their importance for ensuring the survival of humanity in the face of new all-encompassing threats like super volcanoes or mismanaged geoengineering projects. ${ }^{2}$

As we enter an era in which civil defence and crisis preparedness measures are on the rise, it is key to remember past lessons. One motivation for this book lies in its aligning of historical research and contemporary perspectives. Planning, executing and experiencing institutionalised forms of emergency preparedness did not historically-nor does it today-take place in isolation from societal, cultural and political agendas. The chapters in this book also testify to the intricate and complex entwinement of civil defence with regional, national and global contexts. Historical knowledge is relevant to understanding the logic, results and consequences of contemporary attempts to secure the lives of citizens. Thus, we must return to civil defence and study its modes of operation, its material expressions, its underlying policies and mindsets, and not least its imaginary, performative qualities. How were civil defence objectives conceived, how were they implemented and with what consequences for societies and everyday existence? What forms of power were embedded in these systems and practices and how were they exercised?

\section{Historiography, Trends and Aims}

Cold War civil defence already attracted the attention of political and cultural historians in the 1980s (Boyer 1985; Vale 1987; May 1988), but the historiography developed significantly after the end of the Cold War. For a long time, the research field generally focused on conditions in the USA, which coalesced with a more general interest on the part of American contemporary historians in looking back on Cold War culture or 'atomic/nuclear culture' from the vantage point of hindsight. ${ }^{3}$ Studies by Guy Oakes (1994) and Tracy C. Davis (2007) have focused on the entanglement of civil defence, administration and bureaucracy, Kenneth D. Rose (2001) and David Monteyne (2011) have researched the American shelter system, and Laura McEnaney (2000) has demonstrated how the home became a Cold War front line as civil defence contributed to a militarisation of domestic space. Recently, the first truly comparative 
study of the nature of civil defence in the USA and the Soviet Union has appeared (Geist 2019).

When European researchers developed a sustained interest in the history of civil defence, gradually from the early 2000s, one side-effect was an expanded chronological scope. From the clear focus on the 1950s that characterised the scholarship on American Cold War culture, later decades, not least the 1960s and 1980s, began to receive attention. Though the perspectives changed, the themes largely followed those in the established American research field: the organisational and political rationale behind civil defence (Hennessy 2002; Grant 2010), civil defence literature and propaganda (Molitor 2011; Cronqvist 2012; Stafford 2011), the role of cultural norms and emotions in mobilising the citizens around national values (Cronqvist 2015; Biess 2009; Hogg 2016), bunkers and shelter construction (Bennett 2011; Berger Ziauddin 2017b; Bennesved 2020) and the role played by scientific uncertainty about the properties and of radiation in public appraisals of civil defence (Bennett 2018; Sylvest 2020a).

Taken together, the field of civil defence history today displays a rich and productive mix of political and cultural historical perspectives following the so-called cultural turn in the 1990s. While much has been achieved in terms of charting the political significance and cultural dimensions of civil defence, especially within national frameworks, ${ }^{4}$ important dimensions are still missing. With this edited volume, we aim to build on previous research on civil defence by actively seeking to integrate three central dimensions.

First, the role of technology, science and materiality in preparing for and rehearsing the worst warrant more attention. For decades historians have taken an interest in science and technology, as the voluminous subfields of the history of science and the history of technology testify, and the study of material culture is now also well integrated into historical scholarship. Yet, these aspects of history and historical experience have not so far been systematically explored in civil defence history. Several scholars have taken important steps in this direction, ${ }^{5}$ but the field of civil defence history would benefit from a more sustained and theoretically informed focus on these themes.

Second, transnational and comparative perspectives in civil defence history are long overdue. As a subfield of history-a discipline with strong ties to the nation-dealing with a core task of the state, defence, it is 
hardly surprising that it has remained overwhelmingly national in orientation. Still, it is striking how limited our knowledge is about variations both within and between countries when it comes to how civil defence developed as a response to the threat of nuclear war and the effects it had on societies, politics, cultures and citizens. Moreover, existing scholarship has not paid enough attention to the actors and arenas that were central for the transnational circulation of ideas about civil defence and emergency planning. They include international organisations like NATO but also more informal ties between civil defence officials or professionals in allied and neutral countries.

Third and finally, we seek to bring more attention to the divergent and various everyday experiences of civil defence in different contexts. These contexts are not only national, but sometimes also-and perhaps more importantly-local or regional. ${ }^{6}$ Experiences of civil defence also include imaginaries and narratives about Cold War civil defence that inform collective memory, as well as affective patterns or structures that actively contribute to contemporary views of civil defence and the forms of emergency management now enjoying political attention. What Cold War imaginaries linger on in our everyday lives today?

It is in dialogue with the abovementioned historiography on civil defence that this volume seeks to formulate new ambitions for the field and bring together scholarship on Europe during the Cold War. We aim to advance the field by collecting histories of civil defence within an analytical framework that (1) enhances our understanding of similarities and differences in national civil defence efforts as well as in local and transnational dynamics and (2) places special emphasis on the interplay between technology, materiality, culture and politics in civil defence. Individually and collectively, the chapters in this book pursue these aims, and in doing so they operate on three levels of analysis that are highlighted in the organisation of the volume.

The geographical scope of the book is centred on North-Western Europe. We assemble and seek to integrate historical scholarship on civil defence in six European countries-Denmark, Sweden, the Netherlands, West Germany, Switzerland and the UK-and one international organisation, NATO. While the majority of these countries were united by NATO membership and a transatlantic bond, several chapters focus on the role of neutral countries. Sweden and Switzerland are important to include because of their extensive efforts and prominent status in civil defence. After all, these countries allocated the largest funding per capita to civil 
defence in the postwar era (Vale 1987). It is clear that the countries that invested the most in civil defence in the Cold War were indeed those that culturally, materially and financially were not too bruised by the Second World War (Cronqvist 2012).

Chronologically, the focus of the book is the Cold War. However, in contrast to much previous research on Cold War civil defence, our time frame extends well beyond the 1950s and early 1960s in order to grasp some of the interesting trajectories and discrepancies not only between different countries, but also between different periods composing the postwar era. The Cold War is thus more an empirical time frame than a concept with inherent and distinct qualities across more than four decades. As will be apparent in the chapters that follow, other chronologies appear that are equally key to understanding civil defence in its historically and socially situated contexts. Some histories will need to be anchored in the Second World War or the interwar period, while others will resonate with present-day visions of civil defence.

\section{SOCIOTECHNICAL IMAgINARIES: INTRODUCING AND EXPLORING A CONCEPT}

The ambitions of this volume place several demands on our analytical approach. Apart from being attentive to the role of science and technology in social life and being open to transnational dynamics, it also aims to capture some of the most fascinating aspects of civil defence as policy, materiality, practice and vision while being able to accommodate a wide range of themes that coalesced in the institutions, practices and norms of civil defence. We argue that the concept of sociotechnical imaginaries developed by Sheila Jasanoff and Sang-Hyun Kim (2015) provides a productive starting point for exploring new paths in civil defence historiography. In its latest incarnation, Jasanoff has defined sociotechnical imaginaries as

collectively held, institutionally stabilized, and publicly performed visions of desirable futures, animated by shared understandings of forms of social life and social order attainable through, and supportive of, advances in science and technology. (Jasanoff 2015a: 4)

The underlying logic of sociotechnical imaginaries is based on the idiom of co-production, a way of seeing 'knowledge and its material 
embodiments' as 'at once products of social work and constitutive of forms of social work' (Jasanoff 2004: 2). The concept has been developed with the explicit ambition of uniting two views of modernity: a focus on utopias and dystopias prevalent in much political theory (and cultural studies) and a sophisticated understanding of the role(s) of science and technology in social life developed, above all, within Science and Technology Studies (STS).

Apart from a strong attraction to social theory, STS is characterised by a sustained interest in specifying how science and technology matters. ${ }^{7}$ This is clearly reflected in a recent edited volume (Jasanoff and Kim 2015) where the concept of sociotechnical imaginaries is explored on a very broad canvas. The foci of the individual contributions cover a wide variety of topics, some of which deal with themes and dynamics that are related, if indirectly, to central concerns of civil defence history. ${ }^{8}$ As an analytical concept, sociotechnical imaginaries appear to be catching on. An openness towards interdisciplinary scholarship and a theoretical and methodological approach that resonates in the contemporary human sciences are certainly part of the explanation. Substantially, the concept also appears to capture central features of modern existence. Sociotechnical imaginaries provide a gaze on the future that in part serves to structure it. Yet, they are rarely complete nor are they static, and they are often the subject of debate and contestation. ${ }^{9}$

In developing the concept, it has been an explicit ambition of Jasanoff to bridge two binaries that tend to stifle research in the human sciences. The ambition to overcome the first binary, that between ideas and materiality, is reflected in the very term sociotechnical imaginary, and this is, arguably, especially relevant for that large part of civil defence activities that contended with the threats posed by nuclear weapons technologies. After the bombings of Hiroshima and Nagasaki in 1945, few observers doubted the devastation that these weapons could produce; yet, at the same time, it became a peculiar quality of nuclear and later thermonuclear weapons that their subsequent use was restricted to testing and political signalling. Consequently, the threat of nuclear war was both vivid and real, and many of the defensive measures employed had a tangible material quality to them-yet the war itself unfolded in a future that was the province of the imagination (Grant and Ziemann 2016).

The second binary that this approach seeks to transcend, that between agency and structure, points towards analytical strategies that combine 'some of the subjective and psychological dimensions of agency with the 
structured hardness of technological systems, policy styles, organizational behaviours, and political cultures' (Jasanoff 2015a: 24). This ambition fits well with a marked trend in historical scholarship over recent decades: the rapprochement between cultural and political history where the category of 'politics' is expanded to encompass 'the political' and where power is conceived as multidimensional and not merely instrumental. ${ }^{10}$ This ambition must be integral to any history of civil defence intent on venturing beyond personal testimony or organisational history. Even a brief glance at civil defence history highlights the difficulties of separating the political from the cultural-exercises and evacuation plans are obvious cases in point-and recent work is clearly in tune with these broader developments in historical scholarship (e.g. Cronqvist 2015). By foregrounding this ambition, however, Jasanoff encourages scholars to exploit a wide variety of source material that is available. In the case of civil defence, this includes official archives and policy documents, material artefacts and architecture, scientific work and philosophical reflection, official information and popular culture, as well as personal memoires and oral history.

Finally, Jasanoff has concluded the first sustained attempt to demonstrate the reach and insights of the concept by providing a heuristically useful structure for analysing the operation and life cycle(s) of sociotechnical imaginaries. This structure is divided into four phases. The first, origins, examines the mutual imbrication of scientific advances, technological developments, and social and political ideas in their historical context in order to determine how the contours of such imaginaries emerge. The second phase, embedding, is, broadly speaking, concerned with the institutionalisation of an imaginary whereby 'the merely imagined is converted into the solidity of identities and the durability of routines and things' (Jasanoff 2015b: 323). The third phase, resistance, refers on the one hand to the fact that large-scale reorganisations of human societies or their infrastructure typically involved slow and tardy processes. On the other hand, resistance points to the political or normative opposition that is a typical response to the formulation and institutionalisation of new imaginaries. What is resisted, however, can be anything from specific policies to visions of the future and their underlying social norms. The final phase, extension, places special emphasis on how imaginaries travel in time and space, often with the assistance of 'translation agents who are capable of moving imaginaries from one sociopolitical setting to another' (Jasanoff 2015b: 333). 


\section{Applying And Adjusting the Concept}

The concept of sociotechnical imaginaries provides an instructive framework for exploring the hybridity of the ideational and the material that is characteristic of civil defence efforts as they developed during the Cold War. Apart from drawing attention to the intersection of science, technology and social life and facilitating transnational perspectives, there are several, more specific reasons for why the concept is productive and promising to think with in advancing civil defence history.

First, it is highly useful to place technology centre stage in approaching civil defence. After all, civil defence efforts were initially conceived as security measures against technologically mediated, man-made risks, above all forms of warfare that targeted civilian populations from the air by means of conventional explosives and later atomic bombs. In this early phase as well as in later developments, the logic and operation of civil defence were dependent on the employment of new scientific knowledge and a host of modern technologies (from technologies of governance and communication to those of underground construction and radiation detection) in an extensive and often overwhelming quest to ensure the survival of civil society. Science and technology were imbricated in this core rationale from the outset, since the foremost threats were products of weapons technologies based on scientific advances.

This circular logic and central (co-produced) predicament of civil defence became especially urgent and challenging in the nuclear age. It is a predicament, we contend, that comes into sharper focus by approaching civil defence history through the analytical perspective offered by a focus on sociotechnical imaginaries. The reference to desirable futures in the definition of the concept is likely to raise some eyebrows when the concept is applied to civil defence. Yet, notions of the desirable and the undesirable are hard to disentangle, and many of the agents involved in formulating, pursuing, practising or upholding civil defence were not blind to risks or problems but sought to manage, solve or contain them in ways that supported a desirable (or a least undesirable) future. Whether and how such imaginaries were supportive of or opposed to specific developments in science and technology, however, is best seen as an empirical question.

Second, the nature and history of civil defence efforts suggest that they contain a deep, perhaps even constitutive, ambivalence between fear and hope - an ambivalence that has also been found in wider studies of 
nuclear culture (Boyer 1985; Kinsella 2005; Hogg 2016; Sylvest 2020b). Significantly, however, while the hopes invested in civil defence activities may have had utopian qualities (see, e.g., Rose 2001), they just as often reflected a longing for maintaining or extending into a postwar situation the operation of existing norms and aspirations governing social life. The central place accorded to social norms in the study of sociotechnical imaginaries is highly beneficial in this respect. Whether the objective was to prepare for the worst or to discipline citizens (or both), the repeated imagination, rehearsal and contemplation of the next crisis, the next war and the postwar condition were central to civil defence.

The historical analyses in this book turn up many examples of howwithin civil defence organisations, among civil defence personnel and in material civil defence structures - such dynamics translated into complex representations and constructions of technologies, often with a view to entrenching or shifting social norms (see also Clarke 1999). In this context, a key ambition invested in the concept of sociotechnical imaginaries is to illuminate how power relations and governance affect-and are affected by-visions of the role of technoscience in society. The exceptional shelter policy of Switzerland during the Cold War is an instructive case in point. As Berger Ziauddin (2017b: 676-677) has convincingly argued, Swiss nuclear bomb shelter policy can be viewed as a state-led attempt to install 'arrangements of protection and control into the private sphere' with a view to engineering 'docile, calm Cold War subjects'. This extensive quest to produce a 'bomb-proof' society was partly based on and served to extend existing national mindsets relating to the Swiss nation and the role of the family within it. ${ }^{11}$ The ambivalence towards technology underlying this quest - channelled through vivid imaginations of fear and hope in malevolent and positive uses of technology-may even be constitutive of civil defence conceived as a sociotechnical imaginary. ${ }^{12}$

There is, then, ample potential in exploiting the concept of sociotechnical imaginaries for charting new courses in the field of civil defence history. On the other hand, the concept does not constitute a formula that can be applied to civil defence history without adjustments. While useful to think with, the analytical value of central dimensions of the concept can be developed and explored empirically using civil defence as a case. If done right, we suggest historical scholarship on civil defence can therefore both benefit from and contribute depth and texture to the ambitions that inform this approach. While the individual studies in this book display variation not only in how the concept is operationalised in 
relation to specific research questions but also in their reflections on the value of this perspective, the exploration of the concept and its analytical potential undertaken in this volume has been informed by a collective theoretical discussion. Two themes that warrant further elaboration or comment have stood out: the notion of life cycles and the question of scale.

First, while the conceptualisation of a 'life cycle' of imaginaries is heuristically useful, we think the phases identified by Jasanoff are most productively thought of as entangled and potentially reversible processes. In existing civil defence history, processes of (what could be seen as) embedding and resistance have been examined in some detail. It is not hard to see why. The sheer scale and complexity involved in designing, implementing and promoting a wide-ranging system like civil defence has long fascinated historians, just as the multiple forms of resistance such projects encountered-whether geographical, technological, financial, political, aesthetic or psychological-have attracted attention. Similarly, extension is clearly important for advancing the transnational and comparative dimensions of civil defence history, since it directs attention to the circulation, transfer and reception of ideas and artefacts that undergird civil defence conceived as an imaginary.

On the other hand, theoretically speaking it is far from clear whether and how embedding, resistance and extension follow one another or develop simultaneously. For example, embedding is absolutely central in studying civil defence, yet it is not clear at what point embedding takes on the character of extension. The category of origins, while logically predating the other phases and referring to an inescapable facet of historical scholarship, is deceptive. Indeed, to many historians it would be hubristic to straightforwardly claim to have identified the origins of any sociotechnical imaginary, as every apparent innovation is anchored in and remediates other structures, imaginaries and technologies. Several studies have pointed to important continuities between the Second World War and the early Cold War with respect to civil defence (Grossman 2001; Cronqvist 2012), while other studies have emphasised the importance of the interwar imagination of the next war for the development of defence practices during the Second World War (Bennesved and Norén 2020). In short, the linearity with which the notion of a life cycle and its various categories seem to be imbued risk installing a teleological bent in the concept of sociotechnical imaginaries. A great number of historical questions-for example about everyday experiences or memories of 
civil defence or the waxing and waning of the salience of nuclear warare likely to require these processes to be collapsed and studied as deeply entangled, which in turn will disrupt lingering notions of sequence or 'progress'. 13

Secondly, the question of scale presents a practical problem in operationalising the concept of sociotechnical imaginaries for the study of civil defence history. In Jasanoff and Kim's work, the original definition of the concept was national in scope, but for good reasons this has been abandoned. While it does make sense intuitively to speak of national civil defence policies and activities as constituting sociotechnical imaginaries, it may be possible to speak also of local, regional and transnational imaginaries, rival imaginaries or official and unofficial imaginaries just as it may be possible to conceive of forms of resistance as separate imaginaries (Farbøl 2021). In the same vein, imaginaries can be studied at various level of abstraction. Thus, whether civil defence is conceptualised as a separate imaginary in a particular historical context or whether it is best approached as forming part of or intersecting with a broader imaginary operative in a particular time and place (e.g. security politics, industrial modernity or a particular understanding of national purpose) will depend on a combination of empirical factors and the guiding scholarly interest.

In this context, it is also worth highlighting that several contributions to this volume also seek to attune the concept of sociotechnical imaginaries to one of the central challenges of civil defence history: to resist the temptation to study civil defence from the top down and instead to direct scholarship to how it was lived and practised on the ground, which was not always consistent with blueprint designs. Clearly, central dimensions of civil defence history are embedded in the decisions of policymakers and the documents and routines of organisations, but they are also produced by groups and individuals who through training exercises and everyday activities accorded the phenomenon alternative or additional meaning and purpose. In these practices, as they manifested themselves on different levels, we learn more about the 'collectively held, institutionally stabilized, and publicly performed visions' (Jasanoff 2015a: 4) of both peaceful and postwar futures. In the conclusion to this book, we offer further reflections on how the empirical analyses of this volume contribute to the approach. 


\section{OUTLINe OF THE BOOK}

The chapters in this book can be read as independent empirical analyses, but as a collective they provide valuable insights into transnational and translocal connections, similarities and differences in European histories of civil defence. The reader may identify an overall chronological movement from the early 1950s to the 2010 s, but more importantly, there is a three-step thematic movement in the volume. The first two chapters deal predominantly with the planning and structuring of civil defence, the following four chapters largely centre on exercising and communicating civil defence, whereas the final two chapters are concerned with the resisting and remembering of civil defence.

In the following chapter 2, 'Order on Their Home Fronts: Imagining War and Social Control in 1950s NATO', Iben Bjørnsson connects the history of fear to civil defence efforts and analyses the discussions in NATO's Civil Defence Committee and Senior Civil Emergency Planning Committee following the introduction of the $\mathrm{H}$ bomb in the 1950s. By highlighting the relation between security politics and civil defence at a crucial period in the Cold War, the chapter is an ideal starting point for the volume as a whole. The main objective of NATO military and civil defence planners at this time was to secure the morale and obedience of populations by combining previous wartime experiences with scientifically grounded knowledge of the challenges of the thermonuclear age. In her analysis, Bjørnsson argues that the concepts of civil emergency planning and civil defence were closely intertwined with social control and hence also desirable social orders. The chapter also illustrates the importance of a transnational view of civil defence by paying attention to the coordination beyond national borders.

The planning of civil defence is also addressed in Chapter 3, 'The Imagined Disastrous: West German Civil Defence Between War Preparation and Emergency Management 1950-1990', by Jochen Molitor. The experiences of the Second World War were in no other country as complex as in the two Germanies. In the Federal Republic of Germany, the concept of civil defence appeared attractive after notions of 'total defence' had met with resistance and accompanying shelter construction programmes were discontinued. Officials who had initially spoken of 'disasters' to avoid the unpopular term 'war' began focusing on less obtrusive, attainable all-hazards measures such as volunteer relief work from the mid-1960s onward. Similarly, as Molitor shows, the majority of German physicians 
involved in disaster medicine pragmatically imagined scenarios up to, but not exceeding, a nuclear reactor meltdown or isolated nuclear strikes. In the wake of political détente and various technical disasters during the 1980s, most critics came to agree that at least some specialised preparation for more extreme scenarios might be warranted and did not necessarily amount to warmongering.

The following four chapters shift the focus from civil defence as a writing desk product to the different challenges facing the practitioners of civil defence on various levels and in different countries. Exercising and communicating civil defence brings to light the professional and everyday practices. Chapter 4, 'Normalising Nuclear War: Narrative Scenarios, Imaginative Geographies and Sites of Leisure in 1950s Britain' by Jonathan Hogg, directs our attention to the localised social, geographical and discursive contexts in which civil defence was anchored. There is a clear element of planning and structuring here, but since Hogg situates it on a local and not national or transnational level, the enactment and narrativisation of civil defence are at the centre of inquiry. The chapter brings up the narrative scenarios that were created to frame civil defence exercises, their public representation and also the sites of leisure and forms of civic engagement linked to civil defence activity.

Chapter 5, 'Embedding Preparedness, Assigning Responsibility: The Role of Film in Sociotechnical Imaginaries of Civil Defence', studies filmmaking in two neighbouring countries that differed both in terms of their political position in the Cold War and in the scale of their civil defence efforts: Sweden and Denmark. The comparison of the two countries finds a considerable degree of similarity in how films and their circulation were used to frame technologies and script and perform social norms during a period when the $\mathrm{H}$ bomb disrupted existing notions of civil protection. Zooming in on the functions of film in imaginaries of civil defence during the long 1950s, Bennesved and Sylvest argue that the difficulties of embedding sociotechnical imaginaries of civil defence in the early nuclear age are incapsulated in these filmic attempts to recruit volunteers and mobilise citizens for the cause of preparedness.

The thematic focus of Chapter 6 is the role of volunteering women in civil defence, and the scene here is the Netherlands. In "“The World is Her Home': The Role of Women Volunteers in Dutch Civil Defence in the 1950s and 1960s', Dick van Lente compares the efforts to set up and maintain a civil defence organisation with a campaign designed to prepare Dutch women for dealing with the consequences of a nuclear 
attack. Van Lente argues that the relative success of the women's organisation, compared to the poor performance of the male-dominated civil defence organisation, is best pursued in the context of changing views of the general role of women in Dutch society at the time. Indeed, van Lente identifies a conflict between the imaginary of civil defence advanced by Dutch civil defence authorities and the ideals and self-understanding of women volunteers, which was based on a rearticulation of social responsibility in the face of the Cold War.

Chapter 7, 'Ruins of Resilience: Imaginaries and Materiality Imagineered and Embedded in Civil Defence Architecture', brings up yet another area of civil defence practice, namely the material and technological history of civil defence training. Rosanna Farbøl examines a specific architectural phenomenon here, the so-called ruin town, that was built as a civil defence training ground. The phenomenon was present in several countries and Farbøl's particular case is Denmark. By analysing the ruin town as a stage for enacting and performing the anticipated war, she demonstrates how the ruins textualised and spatialised a sociotechnical imaginary that emphasised resilience and regeneration. The material powers of the ruins, in turn, standardised and homogenised the imaginary. In fact, Farbøl argues that ruin towns caused a 'taming' of the nuclear catastrophe and helped reinforce existing social norms and visions of the good society.

The last two chapters in this volume bring up different aspects of reacting to, resisting and remembering civil defence. In Chapter 8, 'Framing Civil Defence Critique: Swiss Physicians' Resistance to the Coordinated Medical Services in the 1980', Sibylle Marti brings up the so-called Coordinated Medical Services in Switzerland, whose task was to create prevention measures for a future nuclear war through an all-encompassing system of underground hospitals and first-aid stations. Marti analyses the criticism and resistance from different groups in the 1980s, and one in particular, Physicians for Social Responsibility (PSR), who refused to serve in the Coordinated Medical Services and in doing so gained much public and media attention. As Marti shows, by envisioning the impossibility and hopelessness of a life after a nuclear war, PSR challenged the authorities' sociotechnical imaginary with widely acclaimed alternatives.

Finally, in Chapter 9, 'Remembering Desirable Futures? Civil Defence Memories and Everyday Life', Marie Cronqvist and Matthew Grant explore to what extent the concept of sociotechnical imaginaries can be 
employed to examine civil defence as remembered. Using oral history sources from Sweden and the UK collected in the 2010s, they discuss the memory work of civil defence on three levels: localities, temporalities and mediations. Their analysis points to not only the ever-present and remaining narratives of resistance in both countries, but also the extent to which civil defence memories tend to diverge from the neat paths of any civil defence sociotechnical imaginary. It also shows that there is a certain 'fuzziness' of everyday life which problematises the binaries set out in the sociotechnical imaginaries framework regarding ideas/materiality and structure/agency.

The concluding chapter of the book provides reflections on the potential and limitations of the concept of sociotechnical imaginaries in historical scholarship. It also sums up the findings in the book as a whole by bringing forth the principal empirical similarities and differences that emerge from the chapters. Finally, we highlight the value of civil defence history for current imaginaries of security for European civil societies in the face of a highly diverse range of real and perceived threats.

\section{Notes}

1. Annex 6, Horizon Europe Programme (HORIZON), Draft Work Programme 2021-2022, 6. Cluster 3: Civil Security for Society, Version 16 October 2020, pp. 140ff.

2. See, for example, Hanson (2008), Baum et al. (2002), Jebari (2015), and Turchin and Green (2017). See also http://immort ality-roadmap.com/sheltersmaps2.pdf (28 January 2021).

3. See Weart (1988, 2012), Whitfield (1991), Henriksen (1997), and Boyer (1998).

4. On USA civil defence history, see, for example, Brown (1988), Oakes (1994), McEnaney (2000), Rose (2001), Garrison (2006), and Davis (2007). On Germany, see Biess (2009), Diebel (2017); on the GDR, see Heitmann (2006). On the UK: Grant (2010), Douthwaite (2019). Canada: Burtch (2011). Sweden: Cronqvist (2012, 2015), Bennesved and Norén (2020), Bennesved (2020). Denmark: Sylvest (2018, 2020a), Farbøl (2020). Switzerland: Berger Ziauddin (2017a, b), and Berger Ziauddin and Marti (2020).

5 . Recent work has ventured into some of these areas. See, for example, Masco (2008), Monteyne (2011), Grant (2019), Deville 
et al. (2014), Douthwaite (2019), Berger Ziauddin (2017a), and Berger Ziauddin and Marti (2020). Cf. also Berger Ziauddin et al. (2018).

6 . Recently, studies of urban civil defence have demonstrated the value of a localised perspective, see Singer (2015), Schregel (2015), and Farbøl (2020).

7. STS scholarship has played a major role in drawing attention to the social import of non-human entities and materialities, how anything from microbes to buildings matters in social life. This dimension of STS scholarship is primarily associated with ActorNetwork Theory (ANT) and the work of Bruno Latour. See Latour (2005).

8. These include studies of US military science policy in the early Cold War (Dennis 2015) and the risk assessments underlying contemporary global health policy (Lakoff 2015).

9. See Sismondo (2020: 505). For examples of recent studies that deploy the concept to study airspaces and oceans as well as sustainable energy provision and the fourth industrial revolution, see Lawless (2020), Robinson (2020), Sovacool et al. (2020), and Schiølin (2020).

10. Especially in Germany, this form of history that places special emphasis on the role of communication in social life has been developed under the heading of 'new political history'. See Steinmetz and Haupt (2013).

11. The intimate relationship between civil defence, identity, statehood and citizenship in the nuclear age has been noted by a number of scholars (including Grant 2011; Cronqvist 2012; Deville et al. 2014; Sylvest 2018).

12. By retrieving visions, structures, practices and materialities of civil defence and exploring their relations to science and technologies, the concept may also carry potential for integrating civil defence with contemporary discussions of cultural heritage. See, for example, the discussion in Rindzevičiūtè (2019).

13. We thank Matthew Grant for raising this concern. 


\section{REFERENCES}

Baum, Seth D., David C. Denkenberger, and Jacob Haqq-Misra. 2002. Isolated refuges for surviving global catastrophes. Futures 72: 45-56.

Bennesved, Peter, and Fredrik Norén. 2020. Urban catastrophe and sheltered salvation. Media History 26 (2): 167-184.

Bennesved, Peter. 2020. Sheltered society: Civilian air raid shelters in SwedenFrom idea to materiality, 1918-1940 and beyond. Malmö: Universus Academic Press.

Bennett, Luke. 2011. The bunker: Metaphor, materiality and management. Culture and Organization 17 (2): 155-173.

Bennett, Luke. 2018. Cold War ruralism. Journal of Planning History 8 (17): 205-225.

Berger Ziauddin, Silvia. 2017a. Superpower underground: Switzerland's rise to global bunker expertise in the atomic age. Technology and Culture 58 (4): 921-954.

Berger Ziauddin, Silvia. 2017b. (De)territorializing the home: The nuclear bomb shelter as a malleable site of passage. Environment and Planning D: Society and Space 35 (4): 674-693.

Berger Ziauddin, Silvia, and Sibylle Marti. 2020. Life after the bomb: Nuclear fear, science, and security politics in Switzerland in the 1980s. Cold War History 20 (1): 95-113.

Berger Ziauddin, Silvia, Peter Bennesved, and Sarah Robey. 2018. Living (again) in an age of nuclear fear: New avenues for studying Cold War civil defense, 16 April 2018. http://www.berlinerkolleg.com/sites/default/files/robey_ berger_ziauddin_bennesved_cold_war_civil_defense_en.pdf [Accessed 11 May 2020].

Biess, Frank. 2009. 'Everybody has a chance': Nuclear angst, civil defence, and the history of emotions in Postwar West Germany. German History 27 (2): 215-243.

Boyer, Paul. 1985. By the bomb's early light: American thought and culture at the dawn of the atomic age. New York: Pantheon.

Boyer, Paul. 1998. Fallout: A historian reflects on America's balf-century encounter with nuclear weapons. Columbus: Ohio State University Press.

Brown, Joanne. 1988. 'A is for atom, B is for bomb': Civil defense in American public education, 1948-1963. Journal of American History 75 (1): 68-90.

Burtch, Andrew. 2011. Give me shelter: The failure of Canada's Cold War civil defense. Vancouver: University of British Columbia Press.

Clarke, Lee. 1999. Mission improbable: Using fantasy documents to tame disaster. Chicago: Chicago University Press

Collier, Stephen J., and Andrew Lakoff. 2008. Distributed preparedness: The spatial logic of domestic security in the United States. Environment and Planning D: Society and Space 26: 7-28. 
Cronqvist, Marie. 2012. Survival in the welfare cocoon: The culture of civil defence in Cold War Sweden. In Cold War cultures: Perspectives on Eastern and Western European societies, eds. Anette Vowinckel, Marcus M. Payk, and Thomas Lindenberger, 191-210. New York: Berghahn.

Cronqvist, Marie. 2015. Evacuation as welfare ritual: Cold War media and the Swedish culture of civil defense. In Nordic Cold War cultures: Ideological promotion, public reception, and East-West interactions, eds. Valur Ingimundarson and Rosa Magnusdottir, 75-95. Helsinki: Aleksanteri Cold War Series.

Davis, Tracy C. 2007. Stages of emergency: Cold War nuclear civil defense. Durham: Duke University Press.

Dennis, Michael Aaron. 2015. Our monsters, ourselves: Reimagining the problem of knowledge in Cold War America. In Dreamscapes of modernity: Sociotechnical imaginaries and the fabrication of power, eds. Sheila Jasanoff and Sang-Huyn Kim, 56-78. Chicago: Chicago University Press.

Deville, Joe, Michael Guggenheim, and Zuzana Hrdličková. 2014. Concrete governmentality: Shelters and the transformations of preparedness. The Sociological Review 62 (S1): 183-210.

Diebel, Martin. 2017. Atomkrieg und andere Katastrophen. Paderborn: Ferdinand Schöningh.

Douthwaite, Jessica. 2019. ' $\ldots$ what in the hell is this?' Rehearsing nuclear war in Britain's civil defence corps. Contemporary British History 33 (2): 187-207.

Farbøl, Rosanna. 2020. Urban civil defence: Imagining, constructing and performing nuclear war in Aarhus. Urban History. https://doi.org/10.1017/ S0963926820000590.

Farbøl, Rosanna. 2021. Prepare or resist? Cold War civil defence and imaginaries of nuclear war in Britain and Denmark. Journal of Contemporary History. https://doi.org/10.1177/00220094211031996

Fridlund, Mats. 2011. Buckets, bollards and bombs: Towards subject histories of technologies and terrors. History and Technology 27 (4): 391-416.

Garrison, Dee. 2006. Bracing for Armageddon: Why civil defense never worked. Oxford: Oxford University Press.

Geist, Edward M. 2019. Armageddon insurance: Civil defense in the United States and Soviet Union, 1945-1991. Chapel Hill: University of North Carolina Press.

Grant, Matthew. 2010. After the bomb: Civil defence and nuclear war in Britain, 1945-1968. Basingstoke: Palgrave Macmillan.

Grant, Matthew. 2011. Civil defence gives meaning to your leisure: Citizenship, participation, and cultural change in Cold War recruitment propaganda 194954. Twentieth Century British History 22 (1): 52-78. 
Grant, Matthew. 2019. Making sense of nuclear war: Narratives of voluntary civil defence and the memory of Britain's Cold War. Social History 44 (2): 229-254.

Grant, Matthew, and Benjamin Ziemann, eds. 2016. Understanding the imaginary war: Culture, thought and nuclear conflict, 1945-90. Manchester: Manchester University Press.

Grossman, Andrew D. 2001. Neither dead nor red: Civil defense and American political development during the early Cold War. New York: Routledge.

Hanson, Robin. 2008. Catastrophe, social collapse and human extinction. In Global catastrophic risks, eds. Nick Bostrom, and Milan M. Cirkovic, 363-737. Oxford: Oxford University Press.

Heitmann, Clemens. 2006. 'Schützen und helfen'? Luftschutz und Zivilverteidigung in der DDR 1955 bis 1989/90. Berlin: Christoph Links Verlag.

Hennessy, Peter. 2002. The secret state: Whitehall and the Cold War. London: Allen Lane.

Henriksen, Margot A. 1997. Dr Strangelove's America: Society and culture in the atomic age. Berkeley: University of California Press.

Hogg, Jonathan. 2016. British nuclear culture: Official and unofficial narratives in the long 20th century. London: Bloomsbury.

Jebari, Karim. 2015. Existential risks: Exploring a robust risk reduction strategy. Science Engineering Ethics 21: 541-555.

Jasanoff, Sheila. 2004. The idiom of co-production. In States of knowledge: The co-production of science and social order, ed. Sheila Jasanoff, 1-13. London: Routledge.

Jasanoff, Sheila. 2015a. Future imperfect: Science, technology and the imaginations of modernity. In Dreamscapes of modernity: Sociotechnical imaginaries and the fabrication of power, eds. Sheila Jasanoff and Sang-Huyn Kim, 1-33. Chicago: Chicago University Press.

Jasanoff, Sheila. 2015b. Imagined and invented worlds. In Dreamscapes of modernity: Sociotechnical imaginaries and the fabrication of power, eds. Sheila Jasanoff and Sang-Huyn Kim, 321-341. Chicago: Chicago University Press.

Jasanoff, Sheila, and Sang-Huyn Kim, eds. 2015. Dreamscapes of modernity: Sociotechnical imaginaries and the fabrication of power. Chicago: Chicago University Press.

Karl, Krystin, and Alex Wellerstein. 2017. About the project. https://reinventi ngcivildefense.org/project [Accessed 3 January 2018].

Karl, Krystin, and Ashley Lytle. 2019. This is not a drill: Lessons from the false Hawaiian missile alert. Bulletin of Atomic Scientists. https://thebulletin. $\operatorname{org} / 2019 / 01 /$ this-is-not-a-drill-lessons-from-the-false-hawaiian-missile-alert [Accessed 11 January 2019]. 
Kinsella, William J. 2005. One hundred years of nuclear discourse: Four master themes and their implication for environmental communication. Environmental Communication Yearbook 2 (1): 49-72.

Lakoff, Andrew. 2007. Preparing for the next emergency. Public Culture 19 (2): 247-271.

Lakoff, Andrew. 2015. Global health security and the pathogenic imaginary. In Dreamscapes of modernity: Sociotechnical imaginaries and the fabrication of power, eds. Sheila Jasanoff and Sang-Huyn Kim, 300-320. Chicago: Chicago University Press.

Latour, Bruno. 2005. Reassembling the social: An introduction to actor-network theory. Oxford: Oxford University Press.

Lawless, Christopher. 2020. Assembling airspace: The single European sky and contested transnationalities of European air traffic management. Social Studies of Science 50 (4): 680-704.

Masco, Joseph P. 2008. 'Survival is your business': Engineering ruins and affect in nuclear America. Cultural Anthropology 23 (2): 361-398.

Masco, Joseph P. 2013. From The nuclear borderlands to the counter-terrorist state: An interview with Joseph P. Masco. Social Anthropology 21: 389-402.

May, Elaine Tyler. 1988. Homeward bound: American families in the Cold War era. New York: Basic Books.

McEnaney, Laura. 2000. Civil defense begins at home: Militarization meets everyday life in the fifties. Princeton: Princeton University Press.

Molitor, Jochen. 2011. Mit der Bombe überleben: Die Zivilschutzliteratur der Bundesrepublik 1960-1964. Marburg: Tectum Verlag.

Monteyne, David. 2011. Fallout shelter: Designing for civil defense in the Cold War. Minneapolis: University of Minnesota Press.

MSB (Myndigheten för samhällsskydd och beredskap). 2018. Om krisen eller kriget kommer [If crisis or war comes]. Karlstad: Swedish Civil Contingencies Agency. Available at: https://www.msb.se/RibData/Filer/pdf/28494. pdf [Accessed 11 May 2020].

Oakes, Guy. 1994. Civil defense and American Cold War culture. Oxford: Oxford University Press.

Rindzevičiūtè, Egle, ed. 2019. Nuclear cultural heritage position paper. HRC Research Networking Project, AH/S001301/1. Kingston upon Thames: Kingston University. Available at: https://nuclearculturalheritage.files.wor dpress.com/2019/11/2019-nuclear-cultural-heritage-position-statement.pdf [Accessed 28 January 2021].

Robinson, Sam. 2020. Scientific imaginaries and science diplomacy: The case of ocean exploitation, Centaurus. https://doi.org/10.1111/1600-0498.12342, $1-21$.

Rose, Kenneth D. 2001. One nation underground: The fallout shelter in American culture. New York: New York University Press. 
Schiølin, Kasper. 2020. Revolutionary dreams: Future essentialism and the sociotechnical imaginary of the fourth industrial revolution in Denmark. Social Studies of Science 50 (4): 542-566.

Schregel, Suzanne. 2015. Nuclear war and the city: Perspectives on municipal interventions in defence (Great Britain, New Zealand, West Germany, USA, 1980-1985). Urban History 42 (4): 564-583.

Singer, Eric. 2015. Civil defence in the city: Federal policy meets local resistance in Baltimore, 1957-1964. Urban History 42 (4): 547-563.

Sismondi, Sergio. 2020. Sociotechnical imaginaries: An accidental themed issue. Social Studies of Science 50 (4): 505-507.

Sovacool, Benjamin K., et al. 2020. Imagining sustainable energy and mobility transitions: Valence, temporality, and radicalism in 38 visions of a low-carbon future. Social Studies of Science 50 (4): 642-679.

Stafford, James. 2011. 'Stay at home': The politics of nuclear civil defence, 196883. Twentieth Century British History 23 (3): 383-407.

Steinmetz, Willibald, and Heinz-Gerhard Haupt. 2013. The political as communicative space in history: The Bielefeld approach. In Writing political history today, eds. Willibald Steinmetz, Ingrid Gilcher-Holtey, and Heinz-Gerhard Haupt, 11-43. Frankfurt: Campus.

Sylvest, Casper. 2018. Atomfrygten og civilforsvaret. temp-tidsskrift for historie 16: 16-39.

Sylvest, Casper. 2020a. Nuclear fallout as risk: Denmark and the thermonuclear revolution. In Histories of knowledge in postwar Scandinavia: Actors, arenas and aspirations, eds. Johan Östling, Niklas Olsen and David Larsson Heidenblad, 21-38. London: Routledge.

Sylvest, Casper. 2020b. Conceptions of the bomb in the early nuclear age. In Non-nuclear peace: The Ban Treaty and beyond, eds. Tom Sauer, Jorg Kustermans, and Barbara Segaert, 11-37. London: Palgrave Macmillan.

Turchin, Alexey, and Brian Turner Green. 2017. Aquatic refuges for surviving a global catastrophe. Futures 89: 26-37.

Vale, Lawrence J. 1987. The limits of civil defence in the USA, Switzerland, Britain and the Soviet Union: The evolution of policies since 1945. London: Palgrave Macmillan.

Weart, Spencer. 1988. Nuclear fear: A history of images. Cambridge, MA: Harvard University Press.

Weart, Spencer. 2012. The rise of nuclear fear. Cambridge, MA: Harvard University Press.

Whitfield, Stephen J. 1991. The culture of the Cold War. Baltimore: The John Hopkins University Press. 
Open Access This chapter is licensed under the terms of the Creative Commons Attribution 4.0 International License (http://creativecommons.org/licenses/ by $/ 4.0 /$ ), which permits use, sharing, adaptation, distribution and reproduction in any medium or format, as long as you give appropriate credit to the original author(s) and the source, provide a link to the Creative Commons license and indicate if changes were made.

The images or other third party material in this chapter are included in the chapter's Creative Commons license, unless indicated otherwise in a credit line to the material. If material is not included in the chapter's Creative Commons license and your intended use is not permitted by statutory regulation or exceeds the permitted use, you will need to obtain permission directly from the copyright holder.

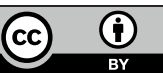

